\title{
A new model of collaborative research: experiences from one of Australia's NHMRC Partnership Centres for Better Health
}

\author{
Sonia Wutzke ${ }^{a, b, f}$, Sally Redmanª, Adrian Baumanna,c, Penelope Hawe ${ }^{a, b}$, \\ Alan Shiella,d, Sarah Thackwaya,e and Andrew Wilson ${ }^{a, b}$
}

a The Australian Prevention Partnership Centre, Sax Institute, Sydney, NSW

b Menzies Centre for Health Policy, University of Sydney, NSW, Australia

c Prevention Research Collaboration, University of Sydney, NSW, Australia

${ }^{\mathrm{a}}$ La Trobe University, Melbourne, VIC, Australia

e Centre for Epidemiology and Evidence, NSW Ministry of Health, Sydney, Australia

${ }^{\dagger}$ Corresponding author: sonia.wutzke@saxinstitute.org.au

\section{Article history}

Publication date: February 2017

Citation: Wutzke S, Redman S, Bauman A, Hawe P, Shiell A, Thackway S, Wilson A. A new model of collaborative research: experiences from one of Australia's NHMRC Partnership Centres for Better Health. Public Health Res Pract. 2017;27(1):e2711706. doi: http://dx.doi.org/10.17061/phrp2711706

\section{Key points}

- Coproduced partnership research is one of the most effective means of increasing the use of research in policy and practice

- National Health and Medical Research Council (NHMRC) Partnership Centres for Better Health are explicitly designed to encourage coproduced partnership research

- Although the Partnership Centre funding model is not without challenges, our early experiences suggest that the unique features of the model, including time, resources and flexibility, enable new ways of working that will deliver relevant, innovative, timely and accessible research for policy and practice

\section{Abstract}

There is often a disconnection between the creation of evidence and its use in policy and practice. Cross-sectoral, multidisciplinary partnership research, founded on shared governance and coproduction, is considered to be one of the most effective means of overcoming this research-policy-practice disconnect. Similar to a number of funding bodies internationally, Australia's National Health and Medical Research Council has introduced Partnership Centres for Better Health: a scheme explicitly designed to encourage coproduced partnership research. In this paper, we describe our experiences of The Australian Prevention Partnership Centre, established in June 2013 to explore the systems, strategies and structures that inform decisions about how to prevent lifestyle-related chronic disease. We present our view on how the Partnership Centre model is working in practice. We comment on the unique features of the Partnership Centre funding model, how these features enable ways of working that are different from both investigator-initiated and commissioned research, and how these ways of working can result in unique outcomes that would otherwise not have been possible. Although not without challenges, the Partnership Centre approach addresses a major gap in the Australian research environment, whereby large-scale, research-policypractice partnerships are established with sufficient time, resources and flexibility to deliver highly innovative, timely and accessible research that is of use to policy and practice. 


\section{Facilitating the use of research in policy and practice}

The value of research for improving health systems is recognised internationally, yet often there is a disconnection between the creation of evidence and its use in policy and practice. ${ }^{1}$ Barriers to the use of research are well documented, including decision makers having insufficient time to read and apply evidence, research not funded to address priority questions, evidence not being produced in the time it is needed, and decision makers not having the capacity to interpret and use the research. ${ }^{2,3}$ Cross-sectoral, multidisciplinary partnership research, founded on shared governance and coproduction, is considered to be one of the most effective means of overcoming this research-policypractice disconnect. ${ }^{4-7}$

Internationally, research bodies have introduced funding schemes to encourage coproduced partnership research, including the US Centers for Disease Control and Prevention's state-based Prevention Research Centers $^{8}$, the UK Collaborations for Leadership in Applied Health Research and Care (CLAHRCs) ${ }^{9}$ and the Canadian Health Services Research Foundation. ${ }^{10}$ In Australia, the National Health and Medical Research Council (NHMRC) has established Partnership Centres for Better Health ${ }^{11}$ : national collaborations of policy, practice and research organisations that focus on a defined theme against a common set of objectives that emphasise collaboration, evidence synthesis, evidence dissemination, implementation and capacity building.

The Partnership Centre funding scheme is embryonic in Australia: two Partnership Centres were established in 2013, with a third recently announced. In this paper, we describe the early experience of one of these centres, The Australian Prevention Partnership Centre (the Prevention Centre) ${ }^{12}$, established in June 2013 as a partnership between the NHMRC, the Australian Government Department of Health, the New South Wales (NSW) Ministry of Health, ACT (Australian Capital Territory) Health and the HCF Research Foundation. The Prevention Centre's research explores the systems, strategies and structures that inform decisions about how to prevent lifestyle-related chronic disease.

Our focus in this paper is on how the different ways of doing research through the Partnership Centre model have worked in practice.

\section{Key features of the Partnership Centre funding model}

Five features of the Partnership Centre funding model are central to the innovation in research epitomised in the Prevention Centre.

First, the model provides funding for a 5-year program of research, creating time for relationships between researchers and policy makers to be developed, and for a shared work program to evolve.

Second, funds allocated by the NHMRC are 'matched' by industry partners either in dollars or in kind, guaranteeing the interest of partners in the direction and achievements of the Partnership Centres and their work. The Prevention Centre initially expected $\mathrm{A} \$ 3.3$ million of in-kind support, and this has now increased to A $\$ 4.5$ million, reflecting increased decision maker engagement.

Third, the direction of the research is guided by a governance authority that includes funding partners. At the Prevention Centre, this group meets quarterly, providing another forum for researchers and funders to work together, understand each other's perspectives, share and translate findings, and agree on new lines of inquiry.

Fourth, the discussion is based around a work plan, developed before the Partnership Centre is initially funded, which reflects priorities identified by funders, and the knowledge and interests of Prevention Centre researchers. In the case of the Prevention Centre, the work plan has provided a basis for agreement about the framework of projects, while also giving flexibility to pursue some questions in more depth or to develop new questions that emerge.

Fifth, the Partnership Centre model explicitly provides funds for coordination, partnership support, synthesis, dissemination and encouraging action. The recognition that complex partnerships need to be resourced has been instrumental in developing strong working relationships in the Prevention Centre, and explicit support for translation has kept a focus on outcomes and the real-world application of the work.

\section{Partnership Centre features encourage different ways of working}

Our early experience is that these five features of the Partnership Centre funding model drive ways of working that are different from both investigator-initiated and commissioned research.

The Partnership Centre model requires shared decision making and commitment to a long-term partnership. In practice, this has meant that there is growing trust among the partners that has enabled us to undertake projects that might not otherwise be possible. For example, although it was not included in the initial work plan, we have been able to undertake research about how governments managed investment and subsequent disinvestment in the National Partnership Agreement on Preventive Health, Australia's largest single investment in preventing the lifestyle risks that cause chronic disease. ${ }^{13}$ This research included interviews with senior state and territory health department staff about 
potentially politically sensitive areas. It required a close collaboration between researchers and policy makers, and the high level of trust within the team resulted in practical, close to real-time recommendations for future large-scale preventive health initiatives. ${ }^{14,15}$

Our research with NSW Health and its Population Health Intervention Management System (PHIMS) is another example. ${ }^{16}$ In this research, we are 'looking under the bonnet' of routinely collected data on the implementation of healthy eating and physical activity programs in child care and primary schools across NSW. The aim is to better understand how local contexts, including resources and capacity, influence program implementation and subsequent health outcomes. Without the level of trust between partners, the researchers would not be able to access potentially sensitive practice-level data.

The Partnership Centre approach fosters coproduction of knowledge between researchers and research users. Before resources are allocated, all projects identify a collaborative team of researchers, practitioners and/ or policy makers that constitute the project team, and outline how they will work together. Our research with NSW Health's PHIMS, as well as our dynamic simulation modelling work (as highlighted in the article in this issue by Atkinson et al. ${ }^{17}$ ), illustrates our approach to coproduction. In the modelling example, we are responding to limitations in traditional evidence synthesis methods by bringing together teams of research, policy and practice partners to collectively develop mathematical models that capture the complex and dynamic nature of 'wicked' problems, as a way of testing strategies for chronic disease prevention before investment.

Our Prevention Tracker research also illustrates our approach to coproduction (Box 1). In this initiative, we are working with local communities to better understand the multisectoral components of their local prevention systems: the people, processes, activities, settings and structures that connect to shape chronic disease risk. The focus of the research and data collection is guided in each community by a local advisory group, including community leaders from local government, Local Health Districts, transport, education, infrastructure and Primary Health Networks. This local advisory group works in partnership with the academic research team to collectively agree on the scope of the research, the design and timing of data collection, and the focus of actions.

We have also used the characteristics of the Partnership Centres to adapt our research agenda beyond the initial work plan to meet emerging needs and interests. The scope of our investment in dynamic simulation modelling, for example, was not anticipated at the outset, but has grown in response to the value placed on these methods by our funding partners. Similarly, in response to an expressed need, a project has been initiated with the HCF Research Foundation to explore the
Box 1. Prevention Tracker: navigating the complexity of chronic disease for improved health

Prevention Tracker began as a flagship project to bring together various elements of the work plan, and try to understand and track the delivery of prevention activities to communities. It soon became an opportunity for real-time use of the insights to strengthen local chronic disease prevention systems, which is what local partners wanted. It now represents an innovative program of partnership research to describe, guide and monitor community-level systems change.

The pilot of Prevention Tracker, implemented in 2015, was coproduced between The Australian Prevention Partnership Centre (the Prevention Centre), Glenorchy City Council and the Tasmanian Department of Health and Human Services, which collectively designed, implemented and interpreted the data collections.

Prevention Tracker brings together community leaders from areas such as local government, Local Health Districts, transport, education, infrastructure and Primary Health Networks. This interdisciplinary, multisectoral team identifies the key underlying causes of chronic disease, and then works collectively to identify and implement solutions. The approach assumes that significant improvements in complex problems will not occur, or be sustained, unless the surrounding system itself - the people, processes, activities, settings and structures, and the relationships between them - is transformed.

Through the pilot of Prevention Tracker in Glenorchy, Tasmania, local leaders now know that there are 55 activities aimed at improving the health of their population, and they understand how the 25 agencies involved in delivering these activities work together. They now have an 'atlas' of indicators that illustrate how the local area of Glenorchy supports a healthy lifestyle, including the density of greengrocers, supermarkets, alcohol outlets and fast food outlets, as well as access to general practitioners, hospitals, parks and green spaces. Further, these leaders have collectively mapped the many interconnected drivers of overweight and obesity in their community, and identified themes of food access, safe and secure environments, and cycles of disadvantage (including the role of poker machines).

Through realignment of the Prevention Centre's work plan, Prevention Tracker has now become established in Glenorchy, and has also expanded to partner with communities in Albany in Western Australia and Broken Hill in NSW. The expanded initiative brings tools, methods and the best available science, as well as local and international expertise, to support communities to collectively tackle their most pressing problems in a timely, meaningful and sustainable way.

I have been grappling with how to get single programs to talk to other programs. Prevention

Tracker has helped us to establish connections that weren't there before. We can see how it will help us work out where best to spend our limited resources. (Kate Garvey, Manager Partnership Development at the Tasmanian Department of Health and Human Services) 
use of incentives to help maintain weight loss achieved during the Foundation's Healthy Weight for Life program. ${ }^{18}$ Both of these projects illustrate how the lines of inquiry of the Prevention Centre have been able to change over time to remain responsive to stakeholder needs.

\section{Different ways of working result in unique outcomes}

Partnership Centres were established to encourage different kinds of research that will have stronger impacts on policy, services, programs and practice. Although it is early days for the Prevention Centre, we can already point to outcomes that we believe emerge from the particular characteristics of the Partnership Centre model.

Together, the longer-term funding and the engagement of end users has enabled us to adopt, adapt and further develop innovative, internationally leading approaches to 'wicked' problems that would have been difficult within other funding schemes. The pilot of Prevention Tracker, for example, enabled community leaders in Glenorchy, Tasmania, to collectively map the many interconnected drivers of overweight and obesity in their community (see Box 1), and new insights helped to identify priority areas for action. One suite of projects is exploring creative ways of increasing public interest in, and support for, prevention policy. ${ }^{19}$ This research involves citizen science (where the public is engaged in collecting data about the world around them $)^{20}$, the compilation of metrics to better communicate the magnitude of health gained by investing in prevention, and working with the arts and entertainment industry. The aim is to lever the power of public values to establish more public support for prevention. Many of these projects may not have been possible within more traditional funding models.

We also anticipate that the Prevention Centre will produce a series of tools for health decision making. We have already developed a range of accessible resources to advocate for prevention, including traditional evidence syntheses, concise fact sheets, and evidence briefs that provide succinct summaries for busy policy makers and practitioners. Our dynamic simulation models provide accessible tools that decision makers can readily interact with to inform their decision making. ${ }^{17}$ We are also developing and making available a number of toolkits, frameworks and methods guides that are of immediate use to policy agencies. These include a toolkit of strategies to inform decisions about the design, implementation and scale-up of prevention programs; a framework to evaluate complex population-level interventions; and guides to build strong business cases for investment in prevention.

We can point to several early examples of our research findings influencing health decisions, in part because of the way that the research was done. This is particularly evident in our National Liveability Indicators project ${ }^{21}$, which uses ongoing research by one of our chief investigators to produce measures of the built environment, and their association with chronic disease risk behaviours and health outcomes. These indicators are being used in urban planning policies from the Victorian Local Governance Association and the Government of Western Australia. The indicator methods have also been used to develop liveability maps for the Prevention Tracker research in Glenorchy (see Box 1); the maps are also used by the Tasmanian office of the Heart Foundation in their materials on the seven myths of food insecurity. Our research on the cost and affordability of healthy diets has informed Australian Government discussions on the goods and services tax (GST) for healthy foods. This research costed people's diets, based on data from the 2011-2013 Australian Health Survey, and compared these with the recommended diet, based on the NHMRC's Australian Dietary Guidelines. It showed that healthy diets were $12 \%$ cheaper than less healthy diets for an average family. ${ }^{22}$ Finally, data from our evidence reviews on chronic disease prevention interventions in children and young adults, and on the costs and benefits of urban form on health, have been used in the National Strategic Framework for Chronic Conditions, and NSW Ministry of Health urban planning with local districts, respectively. These all highlight early examples of the Prevention Centre's research being relevant and useful. We anticipate more examples like this as the Prevention Centre matures.

\section{Concluding remarks}

For the NHMRC, the Partnership Centre model represents a new way of enabling coproduced research, with long-term investment in a continuum of research from discovery to synthesis, communication and action. For other funders, the model offers a mechanism for ensuring that research is responsive and focused on areas of priority for policy and practice, and produces timely outputs in ways that are accessible to users. For researchers, it enables an innovative research space that can address complex problems in ways that would not be possible without the size of the collaboration, its national reach and the diversity of expertise.

The Partnership Centre model is not without challenges. It requires design of, and confidence in, new research governance processes. New approaches for contracts and financing have been required, creating new administrative roles and responsibilities. Coproduction is a cultural change for many players. It can be time consuming and difficult to maintain. When policy makers need results quickly, there is pressure to revert to traditional roles where researchers provide specified services in a specified time. Most of the Partnership Centre investigators have multiple competing commitments that challenge their availability for Prevention Centre work. 
In the face of these potential challenges, the Prevention Centre is committed to reflective practice. We have established a number of mechanisms to scrutinise our decisions, tap international expertise, and document and learn from ongoing evaluation to improve our conduct. We have also established a comprehensive evaluation framework to better understand how the Prevention Centre model contributes to knowledge generation and use. We are tracking the professional networks created by the Prevention Centre to determine whether we are merely centralising the role of existing people and organisations in the prevention system, or creating new capacity. More formal evaluations and lessons will be reported as our work matures. This could well include the identification of a wider set of metrics than those currently used to assess research performance within new collective research enterprises.

Overall, we believe the Partnership Centre approach addresses a major gap in the Australian research environment, whereby large-scale, research-policypractice partnerships are established and sustained, with the time, resources and flexibility to ensure that the overall benefits of research for policy and practice are substantially greater than the sum of the individual research projects.

\section{Acknowledgements}

The Prevention Centre is funded through the NHMRC Partnership Centre grant scheme (grant ID: GNT9100001) with the Australian Government Department of Health, the NSW Ministry of Health, ACT Health and the HCF Research Foundation. The authors would like to thank all the project teams that are undertaking the research we have commented on in this article.

\section{Competing interests}

SW, AW and $\mathrm{PH}$ receive a salary through the NHMRC Partnership Centre grant scheme. The institutions of $\mathrm{SR}, \mathrm{AB}$ and $\mathrm{AS}$ receive funds through the NHMRC Partnership Centre grant scheme to conduct research. ST is an employee of NSW Health, a funding partner of the Prevention Centre. AW is employed by the Australian Government Department of Health as chair of the Pharmaceutical Benefits Advisory Committee.

\section{Author contributions}

SW, SR and AW led the writing, editing and revision of the manuscript. All authors contributed to and approved the final article.

\section{References}

1. Kessler R, Glasgow RE. A proposal to speed translation of healthcare research into practice: dramatic change is needed. Am J Prev Med. 2011;40(6):637-44.

2. Campbell D, Redman S, Jorm L, Cooke M, Zwi AB, Rychetnik $L$. Increasing the use of evidence in health policy: practice and views of policy makers and researchers. Aust New Zealand Health Policy. 2009;6:21.

3. Oliver K, Innvar S, Lorenc T, Woodman J, Thomas J. A systematic review of barriers to and facilitators of the use of evidence by policymakers. BMC Health Serv Res. $2014 ; 14: 2$

4. Dawes SS, Cresswell AM, Pardo TA. From "need to know" to "need to share": tangled problems, information boundaries, and the building of public sector knowledge networks. Public Administration Review. 2009;69(3): 392-402.

5. Gagliardi AR, Webster F, Brouwers MC, Baxter NN, Finelli A, Gallinger S. How does context influence collaborative decision-making for health services planning, delivery and evaluation? BMC Health Serv Res. 2014; $14: 545$.

6. Nutley SM, Walter I, Davies HT. Using evidence: how research can inform public services. Bristol: Policy Press; 2007.

7. Solberg LI, Glasgow RE, Unutzer J, Jaeckels N, Oftedahl G, Beck A, et al. Partnership research: a practical trial design for evaluation of a natural experiment to improve depression care. Med Care. 2010;48(7)576-82.

8. Centers for Disease Control and Prevention: CDC 24/7: saving lives, protecting people. Atlanta, GA: Centers for Disease Control and Prevention. Prevention Research Centers; 2016 [cited 2016 Oct 10]; [about 2 screens]. Available from: www.cdc.gov/prc

9. Rycroft-Malone J, Wilkinson JE, Burton CR, Andrews G, Ariss S, Baker R, et al. Implementing health research through academic and clinical partnerships: a realistic evaluation of the Collaborations for Leadership in Applied Health Research and Care (CLAHRC). Implement Sci. $2011 ; 6: 74$

10. Lomas J. Using linkage and exchange to move research into policy at a Canadian foundation. Health Affairs 2000; 19:236-40.

11. Australian Government: National Health and Medical Research Council. Canberra: NHMRC. Partnership Centres; 2016 Dec 5 [cited 2016 Oct 10]; [about 3 screens]. Available from: www.nhmrc.gov.au/grantsfunding/apply-funding/partnerships-better-health/ partnerships-centres

12. Wilson A, Wutzke S, Overs M. The Australian Prevention Partnership Centre: systems thinking to prevent lifestyle-related chronic illness. Public Health Res Pract. 2014;25(1):e2511401. 
13. Council of Australian Governments. National partnership agreement on preventive health. Canberra: Commonwealth of Australia; 2008 [cited 2 Feb 2017]. Available from: www.federalfinancialrelations.gov.au/ content/npa/health/_archive/health_preventive_national_ partnership.pdf

14. Grunseit A, Rowbotham S, Pescud M, Indig D, Wutzke S. Beyond fun runs and fruit bowls: an evaluation of the meso-level processes that shaped the Australian Healthy Workers Initiative. Health Promot J Austr. 2016;10.1071/ HE16049.

15. Wutzke S, Morrice E, Benton M, Wilson A. What will it take to improve prevention of chronic diseases in Australia? A case study of two national approaches. Aust Health Rev. 2016;10.1071/AH16002.

16. The Australian Prevention Partnership Centre: systems and solutions for better health. Sydney: TAPPC; 2015. Shedding light on how health policies are implemented; 2016 Nov [cited 2016 Oct 10]; [about 2 screens]. Available from: preventioncentre.org.au/our-work/ research-projects/shedding-light-on-how-health-policiesare-implemented/

17. Atkinson J, O’Donnell E, Wiggers J, McDonnell G, Mitchell J, Freebairn L, et al. Dynamic simulation modelling of policy responses to reduce alcohol-related harms: rationale and procedure for a participatory approach. Public Health Res Pract. 2017;27(1):e2711707.
18. The Australian Prevention Partnership Centre: systems and solutions for better health. Sydney: TAPPC; 2015. Losing weight and keeping it off: will incentives help? 2016 Nov [cited 2016 Oct 10]; [about 2 screens]. Available from: preventioncentre.org.au/our-work/ research-projects/losing-weight-and-keeping-it-off-willincentives-help/

19. The Australian Prevention Partnership Centre: systems and solutions for better health. Sydney: TAPPC; 2015. Revealing the unsung heroes of healthy public policy; 2016 Sep [cited 2016 Oct 10]; [about 2 screens]. Available from: preventioncentre.org.au/our-work/ research-projects/1738-2/

20. Bonney R, Cooper CB, Dickinson J, Kellling S, Phillips T, Rosenberg KV, Shirk J. Citizen science: a developing tool for expanding science knowledge and scientific literacy. BioScience. 2009;59(11):977-84.

21. Giles-Corti B, Badland H, Mavoa S, Turrell G, Bull F, Boruff $\mathrm{B}$, et al. Reconnecting urban planning with health: a protocol for the development and validation of national liveability indicators associated with noncommunicable disease risk behaviours and health outcomes. Public Health Res Pract. 2014;25(1):e2511405.

22. Lee AJ, Kane S, Ramsey R, Good E, Dick M. Testing the price and affordability of healthy and current (unhealthy) diets and the potential impacts of policy change in Australia. BMC Public Health. 2016;16:315.

\section{Copyright: (c) (i) (2)}

(C) 2017 Wutzke et al. This article is licensed under the Creative Commons Attribution-NonCommercial-ShareAlike 4.0 International Licence, which allows others to redistribute, adapt and share this work non-commercially provided they attribute the work and any adapted version of it is distributed under the same Creative Commons licence terms. See: www.creativecommons.org/licenses/by-nc-sa/4.0/ 